\title{
A Study of Electric Vehicle Prototype FOR SHELL ECO-MARATHON
}

\author{
Emil Mitev, Simeon Iliev \& Dancho Gunev
}
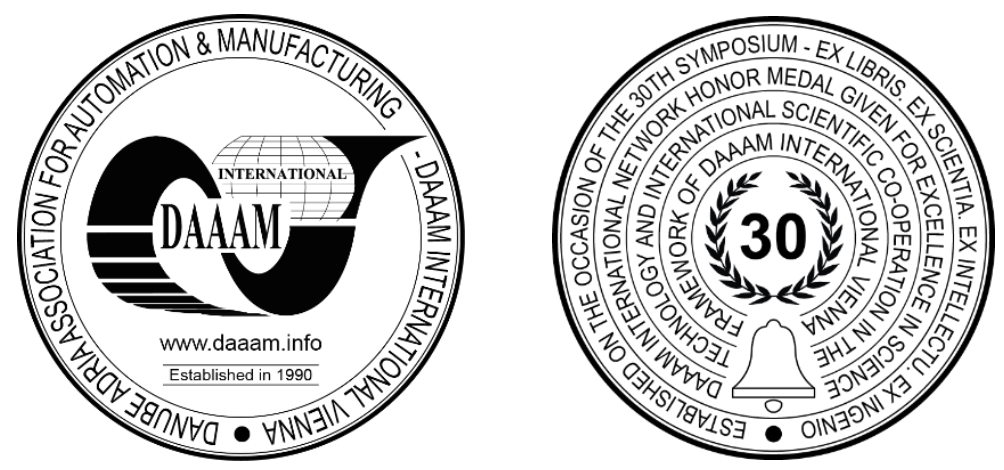

This Publication has to be referred as: Mitev, E[mil]; Iliev, S[imeon] \& Gunev, D[ancho] (2019). A Study of Electric Vehicle Prototype for Shell Eco-marathon, Proceedings of the 30th DAAAM International Symposium, pp.0432-0441, B. Katalinic (Ed.), Published by DAAAM International, ISBN 978-3-902734-22-8, ISSN 1726-9679, Vienna, Austria DOI: $10.2507 / 30$ th.daaam.proceedings.058

\begin{abstract}
The paper reviews the opportunities for developing and researching the suspension's element of an electric vehicle prototype for Shell Eco-marathon competition. The purpose of this particular paper is to examine element of suspension from prototype under specify features, before it can be produced. This suspension element is a subject of a stress test to determine its strength qualities during its exploitation. Thus, its size, weight and way of designing are being optimized to enhance its reliability and reduce the cost of production. Based on obtained results, element with better constructive characteristics has been designed and produced. All information about the shape of the elements in the structure is in electronic form, which allows the use of CAM technology in the elaboration of the individual details.
\end{abstract}

Keywords: Design; Electric Vehicle; Suspension; FEM

\section{Introduction}

The increasing demand for energy efficient electric vehicle, entails the need for improvement of their structures, such as suspension elements, body of vehicle and shape with the lowest possible aerodynamic resistance. The major criteria for the development of these elements are the stiffness and strength enhancement subject to mass reduction as well as cost and time elimination. Lightweight materials, advanced manufacturing processes and special design are set to be the main focus for improving the energy efficiency of electric vehicle's structures [1] and [2].

Generally, a crucial role on the maximization of electric vehicle's efficiency is the achievement of lightweight and stiff vehicle's structures. Hence, structures must be designed optimally to reduce its weight while enhancing overall car performance.

Obviously, the need for lower conceptual design costs in shorter time in conjunction with the need for new modeling techniques, lead the automotive companies to find better ways to develop vehicles.

Simulation through finite element analysis (FEA) is a cost and time efficient way to develop electric vehicle structure whereas at the same time provides innovative product development. Another important point to be considered is the modeling methodology in which a chassis structure is studied. Electric vehicle chassis whereas at the same time provides innovative product development. Another important point to be considered is the modeling methodology in which a chassis structure is studied. 
The production of individual components in the automotive industry is obstructed by a many factor. These factors are monitored from the initial design, during their construction and verification of their functionality until the moment they enter into exploitation. Due to the complexity of their work, some elements require additional upgrades, which cost a lot of resources and time for the manufacturers [3]. This necessitates the use of software product with a high degree of flexibility [4]. The French company Dassault Systems provides the exact CAD software. The architecture of CATIA V5 is based on a modular principle and it includes a set of modules, which correspond to specific engineering tasks or processes [5]. Because of the common user interface on all platforms, the cost is minimized and the efficiency of introducing new opportunities for expanding the scope of use is maximized.

The CATIA V5 platform provides virtual three-dimensional space, in which a three-dimensional object can be created. Also, this object can be subjected to a simulated structural analysis using the finite element method [6]. These features of the CAD product are of critical importance for the creation of a prototype car, due to the costly single-piece manufacturing operations. Two main modules were used to conduct the study and prepare the report: "Part Design", "Assembly Design", "Generative Shape Design" and "Generative Structural Analysis". "Generative Structural Analysis" was used to study the element and „Ergonomics Design and Analysis“" to create a three-dimensional pilot model.

\section{Exposition}

\subsection{Determining the optimal position of the pilot}

To create a three-dimensional virtual model of the pilot's body is used a special "Human Builder" section, which is module in the "Ergonomics Design and Analysis". In order to create such a mannequin, the characteristics of the pilot such as race (European, American, Asian etc), sex, body anthropometry, weight, etc., are introduced. Then, in the same program module, using "Human Activity Analysis" section, is determined the position of the individual parts of the body (Fig. 1), as the mannequin figure is being divided into basic parts, to which a certain values of shrinkage or unfolding can be given, as well as rotation of the individual part of the body.

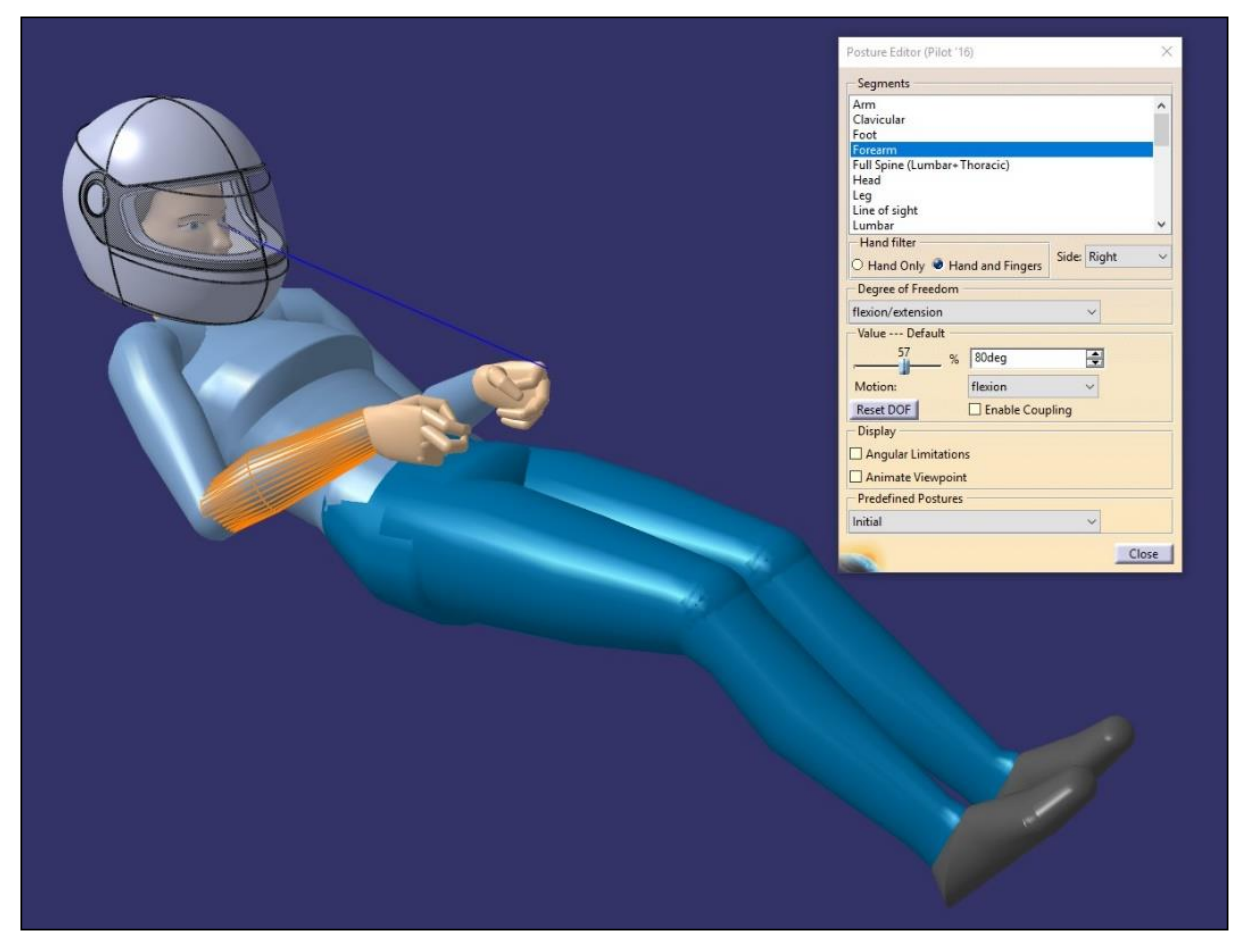

Fig. 1. Window view for determining the angles of rotation of body parts

In the module are planned limit values for the movement of each part of the human body, which enable the pilot's position to be generated in accordance with ergonomic requirements. These requirements preserve their comfortable movement values of the individual parts of the mannequin, while determining what pilot's position will be in the prototype. It should be optimal, both in terms of pilot comfort and aerodynamics in designing the prototype. Once the position of all parts of the body have been precisely defined, the pilot's body can be positioned relative to the horizon (Fig. 2). The pilot is in almost lying position, which preserving comfort and visibility.

As a result of optimization, the height of the space occupied by the pilot, with the safety helmet, is $400 \mathrm{~mm}$ in the vertical direction. 


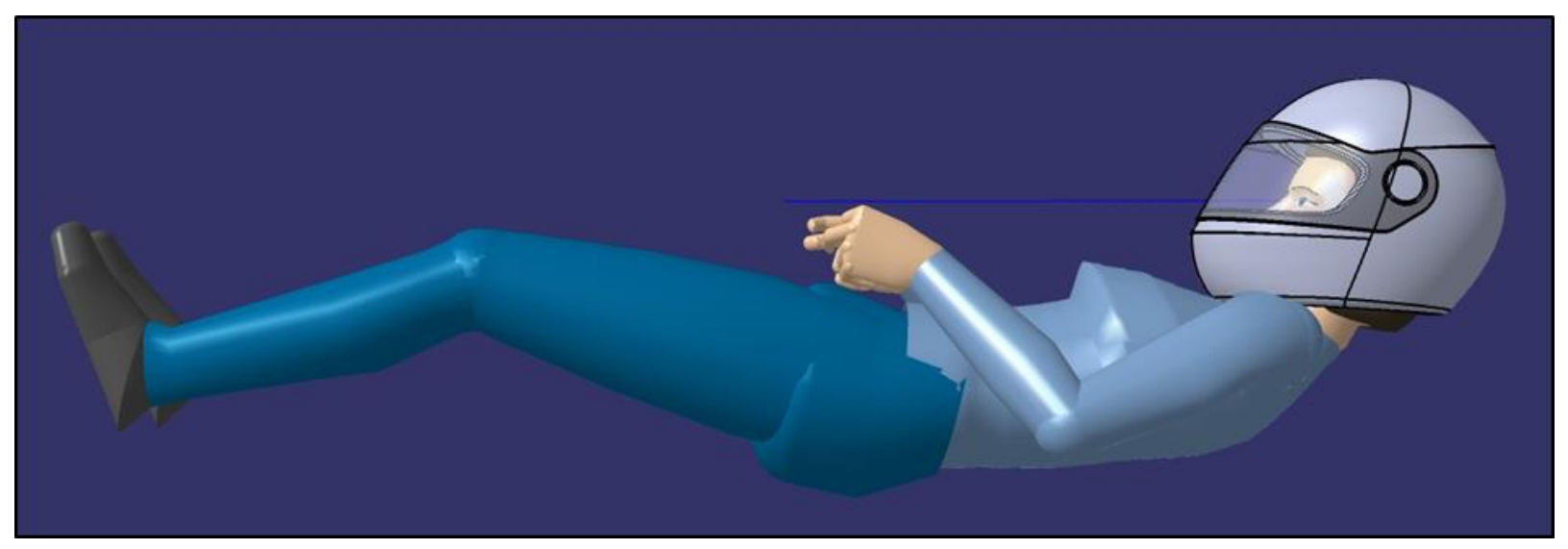

Fig. 2. Position view of the pilot`s body toward the horizon

\subsection{Prototype structure}

The design of the prototype begins with the determination of the pilot's position relative to the wheel position, considering the rule requirements of the Shell Eco-marathon [7]. The production of the main volumes consists mainly in determining the pilot's position, from mass distribution, visibility and conception of constructive features, to the design of the prototype (Fig. 3).

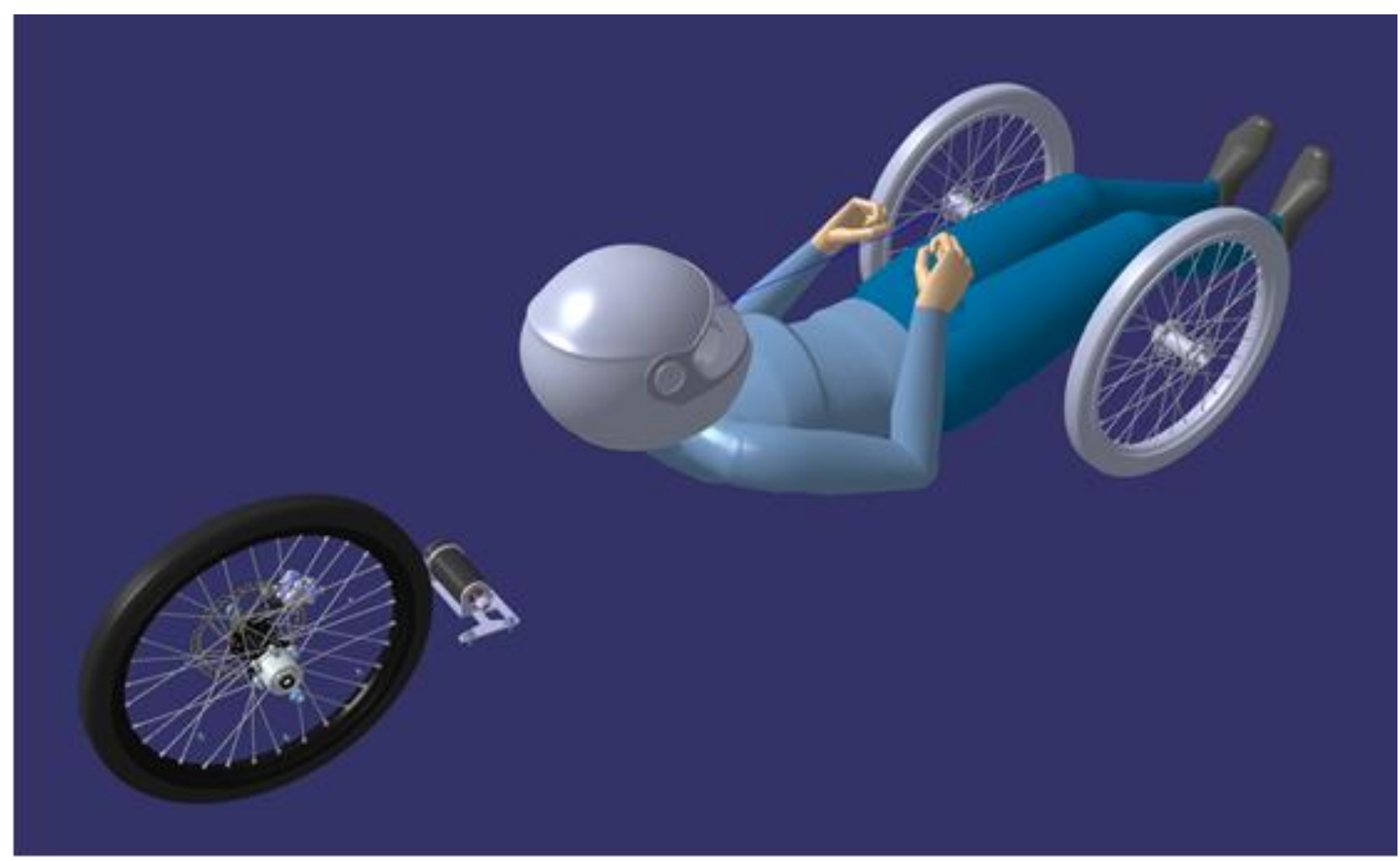

Fig. 3. Positioning the pilot`s body to determine the prototype`s structure

The overall idea of the prototype is to be made by modern technology, using very light and yet robust materials [8]. The body of the prototype is made entirely of carbon, the main purpose of which is to create the shape with the lowest possible aerodynamic resistance (Fig. 4) [9]. The futuristic view of the hull resembles a dripping shape that has a good flowing surface. As shown in Fig. 4, the wheels of the electric car are located inside the hull. As a result, any damage to the suspension, in case of slight contact during a race with another competitor, is prevented. Although, the more important reason is the avoidance of swirling air around the wheels while driving. 


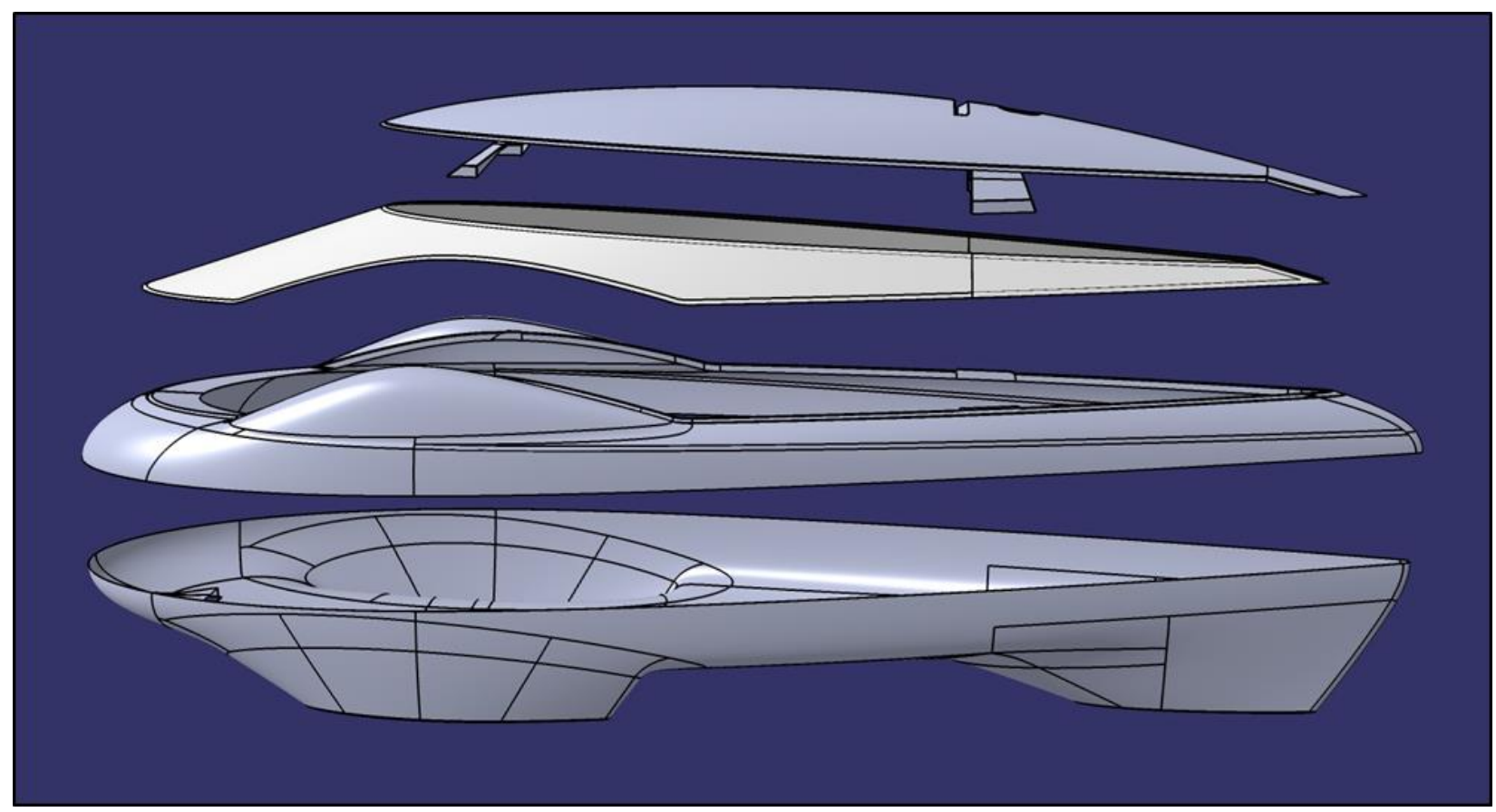

Fig. 4. View of prototype`s body, presented in major components

The construction of the internal element (Fig. 5) is adapted to the pilot's body anthropometry. The process of shaping these element, require considering the overall prototype shape, pilot's location and safety, and the construction of elements that have both an ergonomic role and serve increase the stability of an electric vehicle`s construction. For example, one of the requirements is that the rollbar must withstand a load of 70 kilograms.

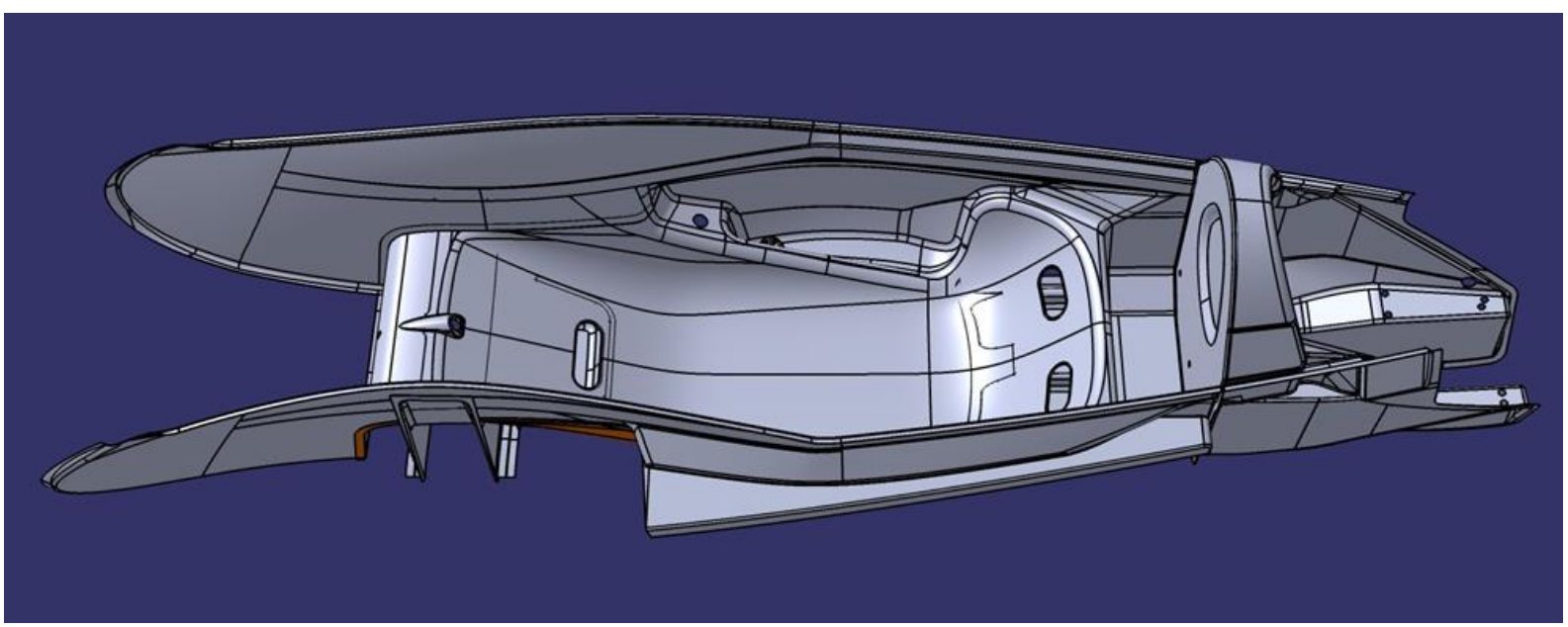

Fig. 5. View of prototype`s interior design elements

\subsection{Suspension design}

The front and rear suspension have a different but similar design. Modern light materials, such as carbon and aluminium alloys, are used to make the prototype. The front suspension consists of a base, two kingpins, two wheels, two braking calipers, two braking discs and steering bars (Fig. 6). The front wheels are steerable, allowing for a turn in a radius of $8 \mathrm{~m}$, but optimized for a $15 \mathrm{~m}$. The majority of the braking effort falls on them. This prevents overloading of the rear suspension and braking effort is distributed over both knuckles. To achieve maximum grip on the road, slick tyres are used. They are tubular with low profile and lightweight, and the maximum allowable pressure is $700 \mathrm{kPa}$.

The determination of wheel alignment is of decisive importance for the final result. Even with the smallest deviation from their convergence, it influences the management and the amount of energy consumed.

The program allows assembly of all parts on the suspension, after determining all tolerances of each element, can be tested for its functionality and to analyse some unforeseen structural features. 


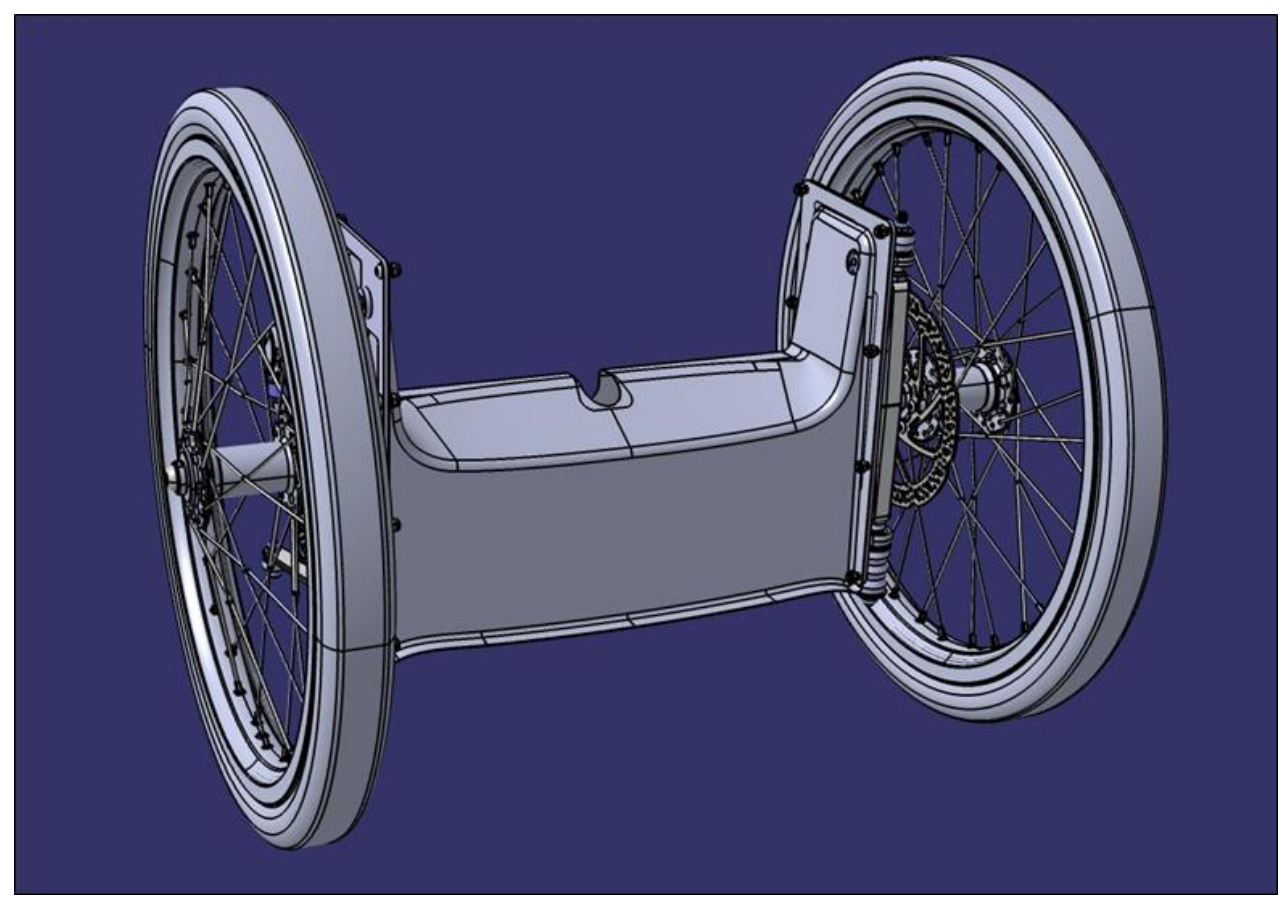

Fig. 6. Prototype`s assembled front axle

Despite the lower number of elements, making the rear suspension is also a difficult task (Fig. 7). The rear wheel is the drive, in order to avoid mounting a differential, which would increase the mass of the prototype. The drive is carried out by transmitting torque from the electric motor to the chain wheel through a tone ring attached to the rear wheel.

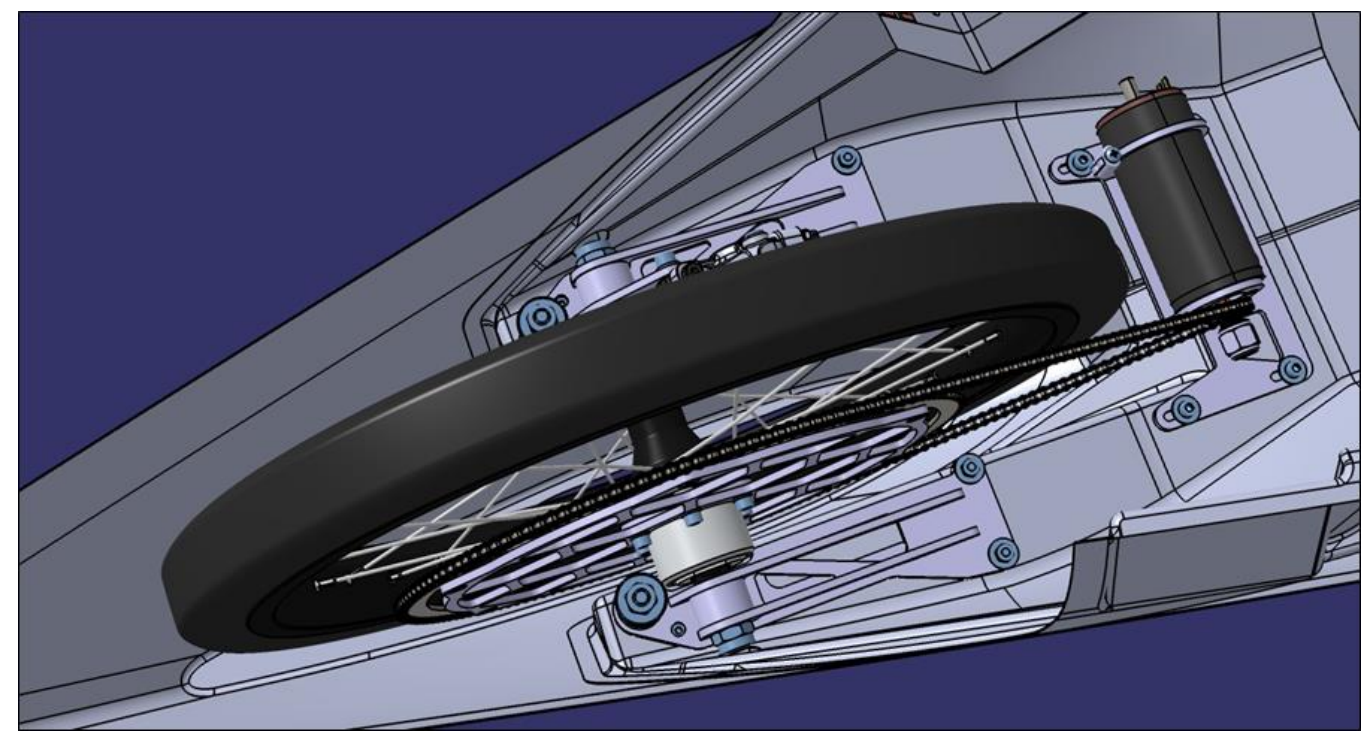

Fig. 7. Prototype`s assembled rear axle

\subsection{Control design}

The design of the DTT-3 prototype has given particular attention to the ergonomic features that influence the pilot. The steering wheel is considerably simplified from switches and convertors (Fig. 8), which helps the pilot to focus on the track. Speed control is accomplished by a "feather" lever, which changes the value of the potentiometer mounted in the steering wheel. The shape of the steering wheel is complianted to the position of the pilot's hands, which help reducing fatigue in the hands while driving. Also, the shape allows a secure and strong grip with conveniently located controls.

The steering wheel has three switches, nicely positioned to work with pilot's thumbs. One of them is responsible for powering the display, while the other two for the vehicle horn and counting the laps.

The display in the centre of the steering wheel provides accurate lap time information, current speed, number of laps, distance past, remaining time and power consumption. 


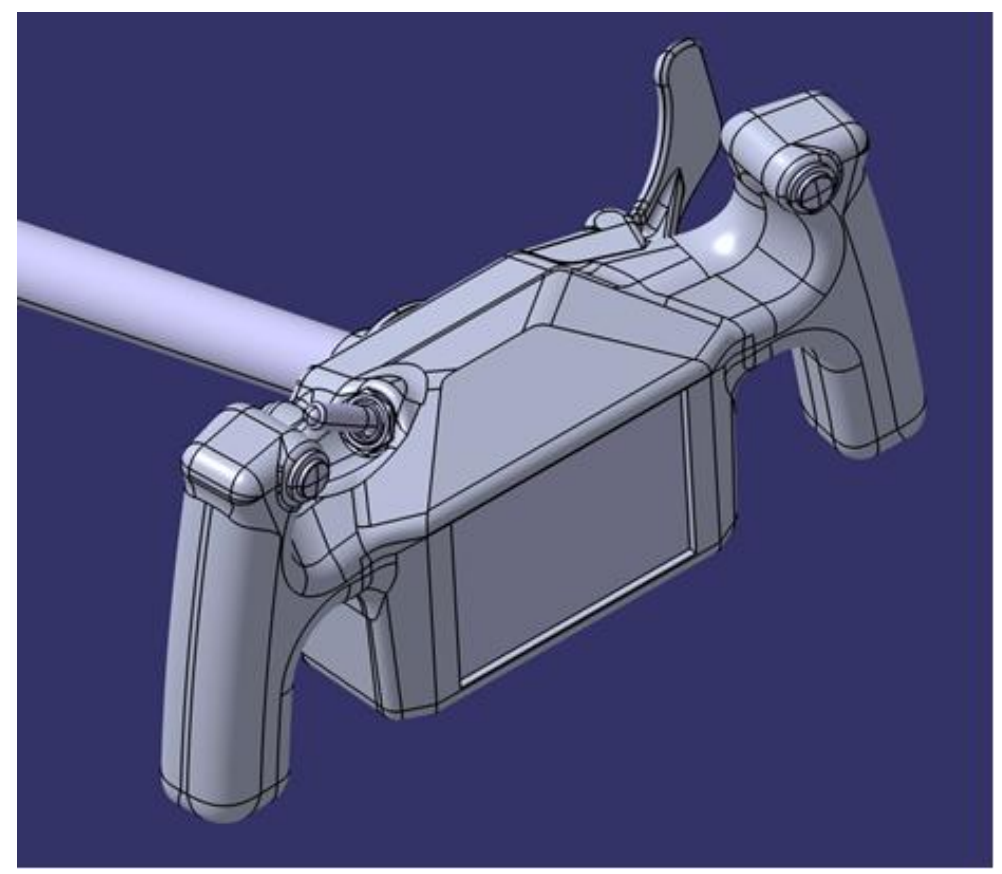

Fig. 8. Three-dimensional design of the steering wheel

The braking mechanism on request by the competition organizers is divided into two rounds for the front and rear wheels. The braking unit is made entirely of aluminium alloy (Fig. 9), consisting of several elements, it allows to be put off at a distance, optimally comfortable for the pilot. The control mechanisms are in form of pedals, which when pressed by foot, push the braking fluid to the braking devices. Under the action of the set pressure in the system, the braking mechanisms push the brake pistons, which press the friction linings to the brake discs on the wheels.

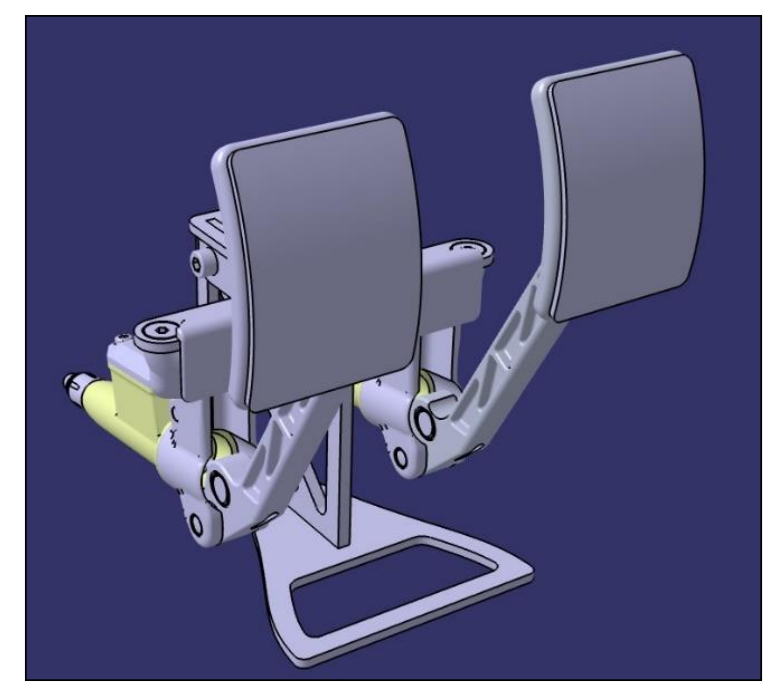

Fig. 9. Three-dimensional design of brake unit

\subsection{Testing of elements of prototype}

In order to reduce the cost of developing details, they need to be pre-calculated or tested though a software product. The Catia V5 allows us to test both individual elements and multiple elements [10]. Firstly, the detail should be designed in "Part Design" module (Fig. 10) and then be set to the technical characteristics of the material, from which to be made. Via "Generative Stress Analysis" module, an element can be easily and quickly tested. Here is presented the test of an element of the front suspension of the prototype - the kingpin. It is the basic element because it attaches the braking system and wheel. 


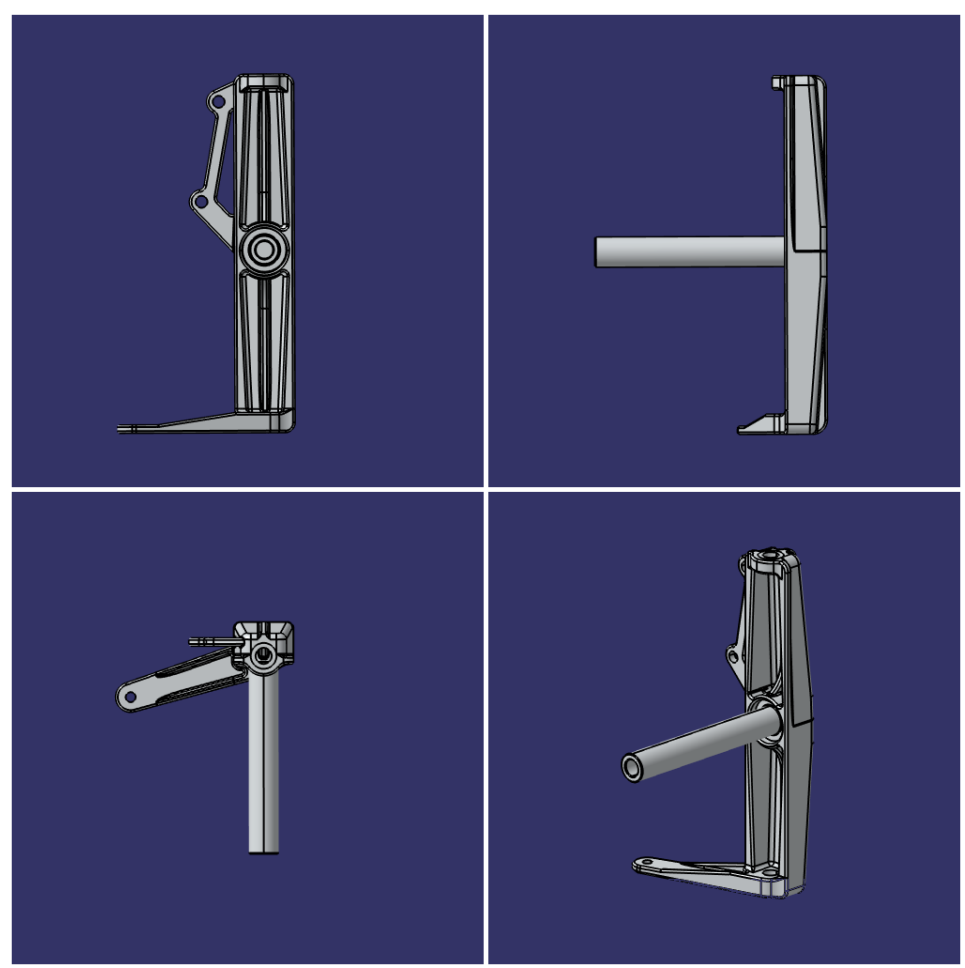

Fig. 10. Projections of the designed element

The test detail is presented in Fig. 10. After the three-dimensional model has been drawn, the degree of freedom of the element is restrained (Fig. 11). Once the limitations have been set, the forces and moments acting on the element, with their directions and values, are determined (Fig. 12). In this case, the test is at full load.

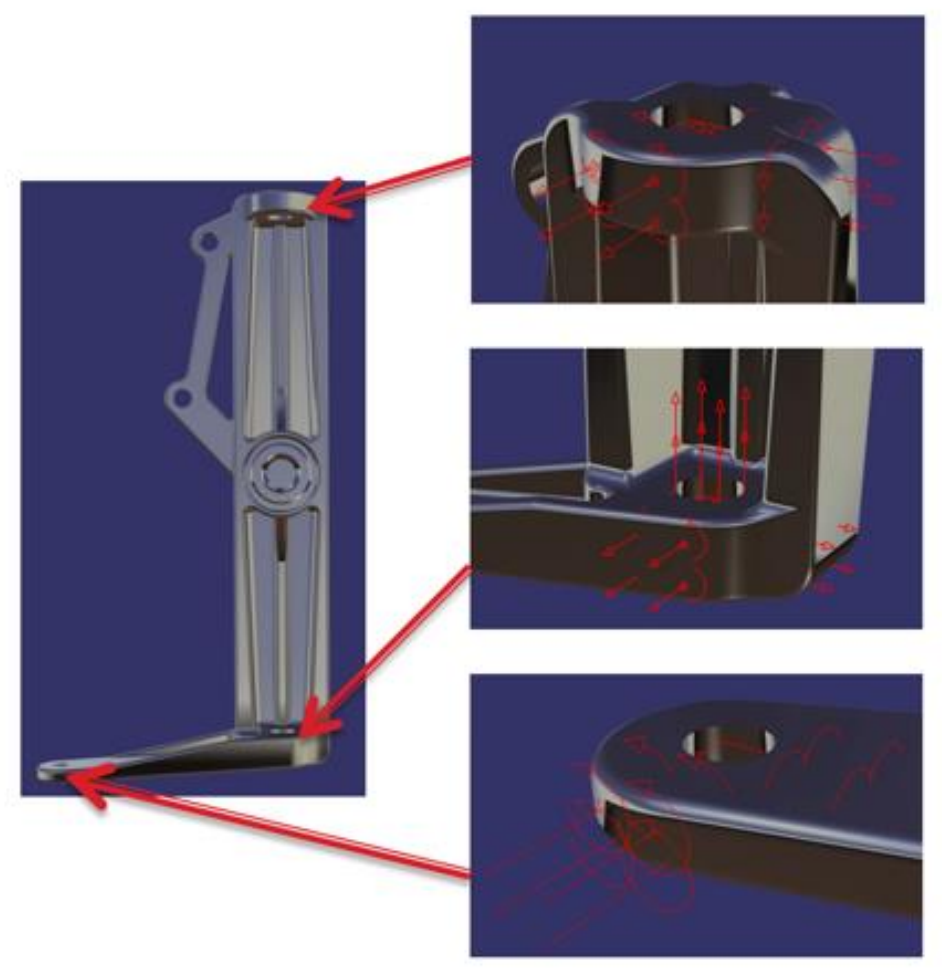

The restriction is:

Rotation of axle: $\mathrm{X}$ and $\mathrm{Y}$

Move on: $\mathrm{X}$ and $\mathrm{Y}$

The restriction is:

Rotation of axle: $\mathrm{X}$ and $\mathrm{Y}$

Move on: $\mathrm{X}, \mathrm{Y}$ and $\mathrm{Z}$

The restriction is:

Rotation of axle: $\mathrm{X}$ and $\mathrm{Y}$

Move on: $\mathrm{X}$ and $\mathrm{Y}$

Fig. 11. Limiting degrees of freedom 


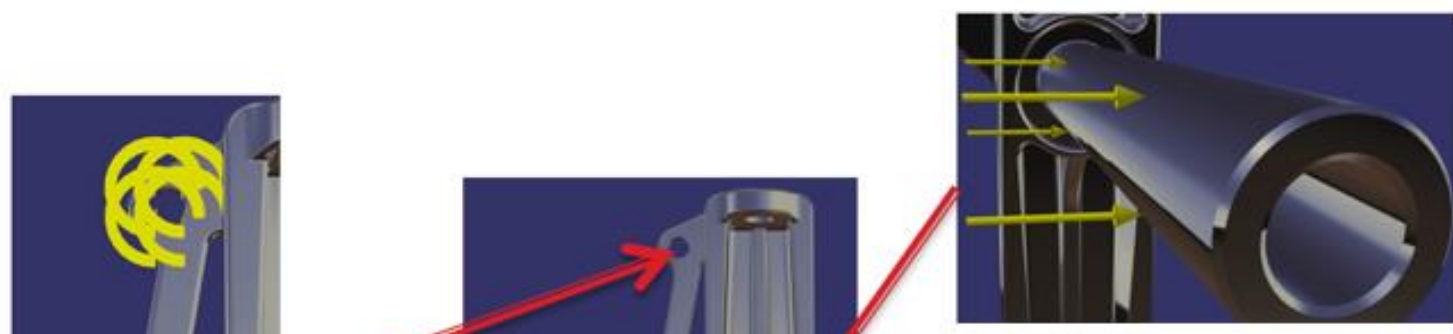

Wheel axle load from the inertial force of the prototype $250 \mathrm{~N}$ on $\mathrm{X}$ axle

The anchor opening's moment of the brake caliper $60 \mathrm{Nm}$ to wheel axle
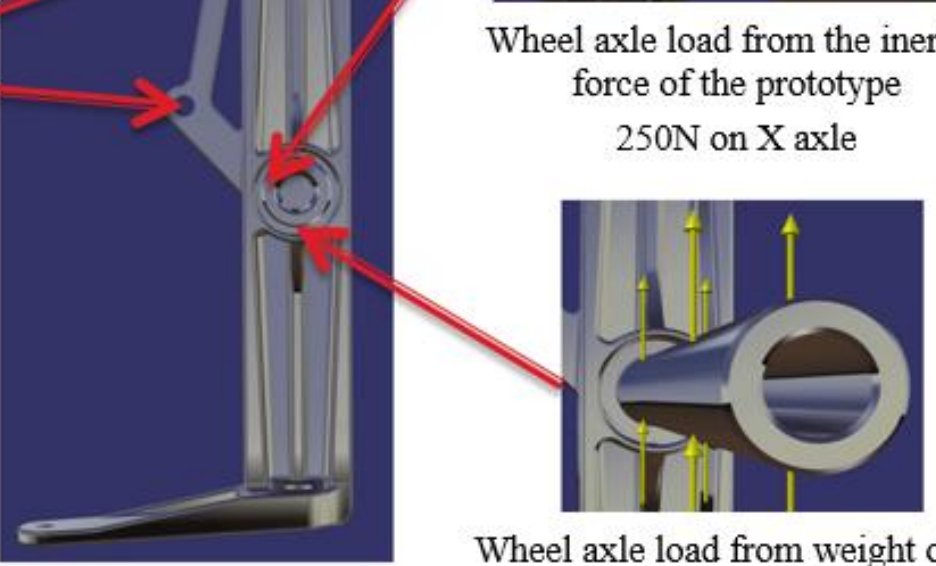

Wheel axle load from weight of the prototype and the pilot $350 \mathrm{~N}$ on $\mathrm{Y}$ axle

Fig. 12. Applying the forces and moments acting on the suspension element

Once the limits and forces acting on the element have been determined during braking, the software automatically calculates the load. Results are produced for maximum boundary drag and point displacement (Fig. 13 and Fig. 14).

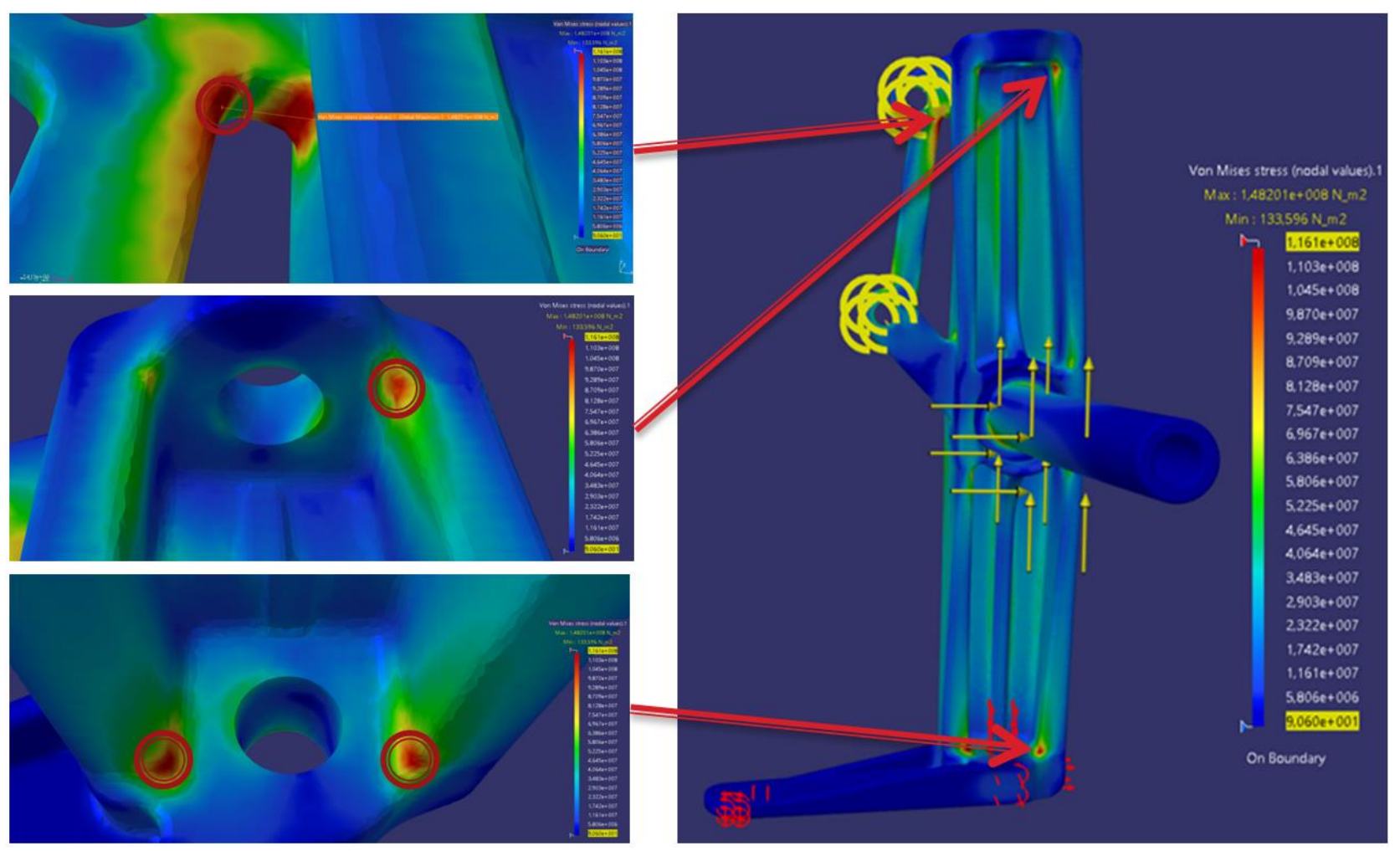

Fig. 13. Suspension element`s test results 


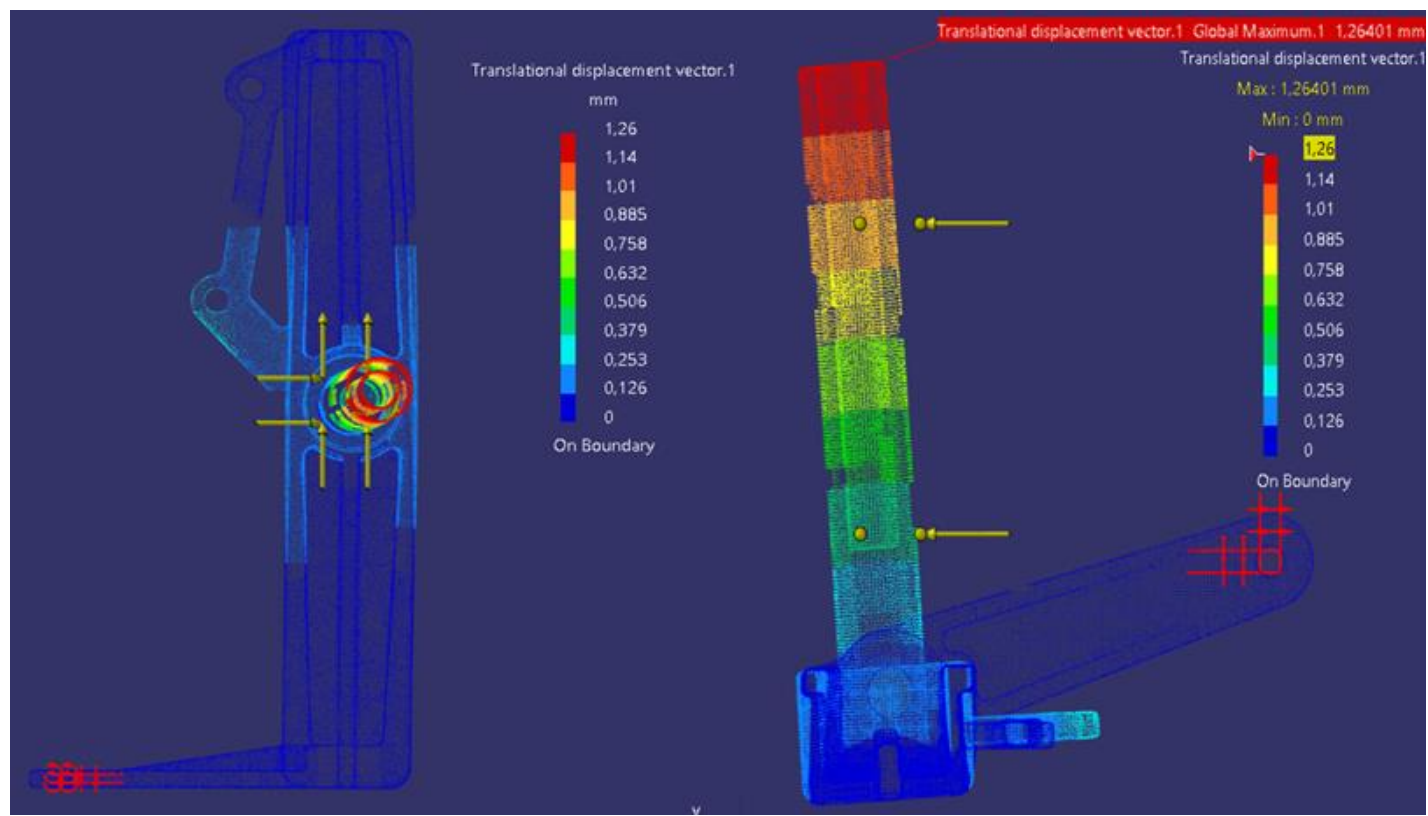

Fig. 14. Suspension element`s test results

\section{Conclusion}

Due to the use of Simulation through FEA, CAD/CAM technology, lightweight materials, advanced manufacturing processes and special design many of the prototype`s parameters have been optimized:

- Weight reduction by $40 \%$ over the previous DTT-2, as a result of optimization of shape and materials used during design. The weight of individual elements is reduced by removing material from areas with lower voltages or by removing some ribs.

- Using the CATIA ergonomic module, an optimal working position of the pilot has been achieved, without the need for a test rig and a real pilot. This greatly reduces the time for designing and making the right decisions.

- All information about the shape of the elements in the structure is in electronic form, which allows the use of CAM technology in the elaboration of the individual details. This in turn leads to more precise workmanship and reduction of prototype`s assembling problems.

- Excellent consideration of driver ergonomics, comfort and safety

As the future plan of the experiment team will investigate behaviour of electric vehicle with a newly developed controller that aims to reduce energy consumption.

\section{Acknowledgments}

The study was supported by contract of University of Ruse “Angel Kanchev”, № BG05M2OP001-2.009-0011-C01. Support for the development of human resources for research and innovation at the University of Ruse "Angel Kanchev". The project is funded with support from the Operational Program" Science and Education for Smart Growth 2014 - 2020" financed by the European Social Fund of the European Union.

The present document was supported with the financial assistance of the Project 2019-RU-03.

\section{References}

[1] Lv, C.; Hu, X.; Sangiovanni-Vincentelli, A.; Li, Y.; Martinez, C.M.; Cao, D. (2019) Driving-Style-Based Codesign Optimization of an Automated Electric Vehicle: A Cyber-Physical System Approach. IEEE Trans. Ind. Electron, 66, 2965-2975.

[2] Tang, X.; Yang, W.; Hu, X.; Zhang, D. (2017) A novel simplified model for torsional vibration analysis of a seriesparallel hybrid electric vehicle. Mech. Syst. Signal Process, 85, 329-338.

[3] Antonova, D., Stoycheva, B. (2018). Approved model of factors, influencing the management process in developing new products. In: The 6th International Conference Innovation Management, Entrepreneurship and Sustainability (IMES 2018), Czech Republic, Vysoká škola ekonomická v Praze, Nakladatelství Oeconomica - Praha, 2018, Nakladatelství Oeconomica, pp. 38-54.

[4] Prof. Univ, S. T. P. (2016). CATIA V5-6R2015 for Designers, 13th Edition. CADCIM Technologies; 13 edition. ISBN-13: 978-1942689218 
[5] Petrova, Tz. (2016). Guide for engineers and students. Part 1: CATIA V5. Design of machine-building details. Plovdiv: "Haycad Infotech Publishing". ISBN 978-619-7365-01-6.

[6] Zamani, N. G. (2012). CATIA V5 FEA Tutorials: Release 21. SDC Publications.

[7] SHELL ECO-MARATHON, 2019 OFFICIAL RULES, CHAPTER I

[8] Iliev, S., Gunev D., Dobrev V. (2017). Improving engineering education through the design and manufacture of electric car for the Shell Eco-marathon competition, ERS Spectrum (Educational Research Service), Vol. 29, No. 2, ISSN: 0740-7874

[9] Tuzharov, K., Iliev, S., Gunev, D. (2018). Aerodynamic Study of the Environmental Vehicle Model with the Flow Simulation CFD Program, Proceedings of the 29th DAAAM International Symposium, pp.0495-0504, B. Katalinic (Ed.), Published by DAAAM International, ISBN 978-3-902734-20-4, ISSN 1726-9679, Vienna, Austria, DOI: 10.2507/29th.daaam.proceedings.072

[10] Weaver, J. M., Zamani, N. G. (2012). CATIA V5 Tutorials Mechanism Design \& Animation Release 21. SDC Publications. ISBN: 978-1-63056-056-0 